\title{
Controlling morbidity and interrupting transmission: twin pillars of lymphatic filariasis elimination
}

\author{
Controle da morbidade e interrupcão da transmissão: \\ dois pilares da eliminação da filariose linfática
}

\author{
A.R. Seim, G. Dreyer and D.G. Addiss
}

In recent years, lymphatic filariasis has emerged as an increasingly important public health problem in several areas around the world2 12. An estimated 120 million persons in Africa, southern Asia, the western Pacific Islands, the Atlantic coast of South and Central America, and the Caribbean are affected; of these, estimated 44 million persons suffer from lymphedema of the extremities or urogenital disease 20 . The physical debilitation, social stigmatization, and economic losses associated with lymphatic filariasis make it the second leading cause of disability worldwide ${ }^{19}$.

The development of new approaches and tools for diagnosis and safe, effective mass treatment of persons infected with the parasite has provided new hope that Wuchereria bancrofti, the cause of $>90 \%$ of human lymphatic filariasis worldwide, can be eliminated and that transmission of Brugia malayi, the other major lymphatic filarial parasite, can be significantly reduced. In 1993, the International Task Force for Disease Eradication identified lymphatic filariasis as one of only six diseases that are eradicable or potentially eradicable6, and in May, 1997, the World Health Assembly passed a resolution calling for global elimination of lymphatic filariasis as a public health problem (WHA 50.29).

To discuss the implications of this resolution and to make recommendations for implementation of a global elimination programme, a policy retreat was held on July 15-17, 1997 on Magnetic Island, off the coast of Townsville in Queensland, Australia. Nineteen persons attended, including scientists, administrators, representatives of the
World Health Organization and two of its Collaborating Centers for Lymphatic Filariasis, and representatives from ministries of health, non-governmental organizations, academia, and industry. Discussions focused on the goals and objectives of the programme, the technical and logistical steps necessary for its implementation, integration with other public health and disease control initiatives, development of linkages with a variety of public and private partners, and the need for data on the costs of the disease, its treatment, and its control.

The principal conclusion of the meeting was that elimination of lymphatic filariasis as a public health problem is feasible, and that it will require a dual approach. First, programs at local, national, and global levels must relieve current suffering. Second, these programs must interrupt transmission to prevent disease in future generations. Relief of suffering will need to be a critical component of filariasis elimination programs because interruption of transmission alone has no short-term effect on the prevalence or incidence of chronic disease, particularly elephantiasis of the leg and advanced urogenital disease 10 , and because addressing the needs of those already affected enhances community acceptance of measures to interrupt transmission. In parts of Taiwan, for example, where transmission has essentially been eliminated, lymphedema and elephantiasis continue to be important public health problems 10 . The dual approach recommended by the participants at this meeting (i.e., both relief of suffering and interruption of transmission) differs from that of

Health and Development International in Norway, Centro de Pesquisas Aggeu Magalhaes/FIOCRUZ, Recife, PE, Brazil, and Centers for Disease Control and Prevention, Atlanta, GA, USA.

Address to: Drª Gerusa Dreyer. Av. Prof. Moraes Rego s/no․ Câmpus Universitário, Cidade Universitária, 50670-420 Recife, PE, Brasil. Recebido para publicação em 9/2/99. 
campaigns to eradicate smallpox and guinea worm, which have focused almost exclusively on interrupting transmission.

Relief of suffering. For the estimated 15 million persons with lymphedema of the extremities caused by lymphatic filariasis, effective treatment is now available that is both inexpensive and sustainable. Recent work has shown that lymphatic vessel dilatation induced by the presence of the adult worm eventually leads to lymphatic dysfunction. The lower limbs, in particular, become predisposed to recurrent bacterial infections. The vast majority of acute attacks of lymphangitis in filariasis-endemic areas are caused not by the filarial parasite but by secondary bacterial infections 1715918 ; lymphatic damage related to the adult worm results in increased susceptibility to these repeated bacterial infections, which lead to progression of lymphedema and elephantiasis. The central core of lymphedema treatment is the prevention of these acute attacks through basic hygiene using soap and water, and through cure and prevention of small skin lesions with application of topical antifungal and antibiotic cream. Experience from Brazil and Haiti suggest that this approach is feasible at the community level and that it can stop acute attacks, which prevents lymphedema progression and causes a certain degree of regression, even in advanced cases.

An estimated 29 million men have urogenital manifestations of lymphatic filariasis, including hydrocele, chylocele, and lymphedema and elephantiasis of the scrotum and penis. Hydrocele can be successfully treated with simple surgery. The ability to provide this treatment will depend on the resources and infrastructure of each country. Similar to the legs, the skin of the scrotal wall and penis are prone to secondary bacterial infections and acute attacks. Basic hygiene can stop the acute attacks in the genital area and improve the patient's condition, although the definitive solution for advanced lymphedema and elephantiasis of the genitals is still under investigation. Relief of suffering for these chronic conditions will require innovative strategies and additional resources.

Interruption of transmission. Research during the past few years has demonstrated that a single $6 \mathrm{mg} / \mathrm{kg}$ dose of diethylcarbamazine (DEC) is virtually as effective in killing adult $W$. bancrofti and in producing long-term suppression of microfilaria in the blood as the previously recommended 12-day course of treatment 73 ; that single-dose ivermectin $(400 \mu \mathrm{g} / \mathrm{kg})$ is even more effective than DEC in suppressing microfilaremia 814 ; and that the long-term microfilarial suppression of DEC and ivermectin is enhanced when they are given together 816 or with albendazole 113 . When both ivermectin and $\mathrm{DEC}$ are given to all eligible community members once a year, microfilaremia rates drop dramatically and measures of infectivity in the mosquito vectors also decrease 5 . The enhanced microfilarial suppression of the two-drug regimens and their broader spectrum of action against intestinal parasites also makes them more attractive for mass treatment programs. The manufacturer of albendazole, SmithKline Beecham, recently announced the donation of albendazole to assist in elimination of lymphatic filariasis worldwide. Until the donated drug is widely available, several countries are proceeding with mass treatment using annual single-dose DEC4. In parts of Africa where onchocerciasis and loaiasis occur, the potential for severe adverse reactions associated with DEC make mass treatment with this drug unacceptable. In these areas, the combination of ivermectin and albendazole is likely to be the favored drug regimen. For all of these drugs and drug combinations, the level of coverage in the population and the duration of treatment required to interrupt transmission are not yet precisely known.

Co-fortification of salt with both iodine and DEC may be a useful adjunctive approach. This strategy has been shown to interrupt transmission in China 11 , and projects are currently underway to evaluate the feasibility and effectiveness of this strategy elsewhere.

Recommendations and needs. The principal finding of the meeting was that "the time is right to undertake a global programme whose goal is to eliminate lymphatic filariasis as a public health problem both by (i) reducing suffering through community-based care and treatment of affected patients, and by (ii) interrupting the spread of infection". However, critical needs must be addressed before the global elimination programme can be fully implemented. These include:

- improved assessment of the economic burden of filariasis and the costs of its control;

- more accurate understanding of the global distribution and prevalence of filariasis;

- development of specific technical guidelines and training materials; 
- creation of an active WHO technical advisory group to help guide the programme, including representatives of the various partners involved in the elimination effort;

- greater advocacy efforts at all levels;

- development of international and nationallevel partnerships with both governmental and non-governmental organizations.

At the same time, a critical need exists for further basic, clinical, epidemiologic, and operational research to:

- develop surveillance techniques for initial assessment, program monitoring and certification of elimination;

. improve treatment for men with urogenital disease;

- develop and validate improved laboratory techniques for rapid diagnosis and assessment of exposure to the parasite, including entomologic indicators.

The Policy Retreat was co-sponsored by: Health and Development, International (HDI); The
Division of Control of Tropical Diseases (CTD), World Health Organization (WHO); James Cook University (JCU), Townsville, Australia; the U.S. Centers for Disease Control and Prevention (CDC); the Australian Agency for International Development (AusAID), and the Carter Center. Meeting participants included: David Addiss (CDC); Gautam Biswas, National Institute of Communicable Diseases, India; Denis Broun, UNICEF, United States; Gerusa Dreyer, FIOCRUZ, Brazil; John Gyapong, Ministry of Health, Ghana; R.H. Henderson (WHO); Arthur Hood, Placer Dome Inc, Papua New Guinea; Donald R. Hopkins, The Carter Center; Jacquie L. Kay (HDI); Clement Malau, South Pacific Commission, New Caledonia; Mya Thein Han, Ministry of Defense, Myanmar; Nay Soe Maung, Department of Public Health, Myanmar; Eric Ottesen (WHO); C.P. Ramachandran, Universiti Pertanian Malaysia; D. Richard-Lenoble, Faculty of Medicine, Tours, France; Anders R. Seim (HDI); Jaime Z. Galvez Tan, UNICEF, The Philippines; Paul Turner (JCU); and lan Wronski (JCU).

\section{REFERENCES}

1. Addiss DG, Beach MJ, Streit TG, Lutwick S, LeConte FH, Lafontant JG, Hightower AW, Lammie PJ. Randomised placebo-controlled comparison of ivermectin and albendazole alone and in combination for Wuchereria bancrofti microfilaremia in Haitian children. Lancet 350: 480-484, 1997.

2. Albuquerque MFM, Marzochi MC, Ximenes R, Braga MC, Silva MCM, Furtado AF. Bancroftian filariasis in two urban areas of Recife, Brasil: The role of individual risk factors. Revista do Instituto de Medicina Tropical de São Paulo 37: 225-233, 1995.

3. Andrade LD, Medeiros Z, Pires ML, Pimentel A, Figueredo-Silva J, Coutinho A, Dreyer G. Comparative efficacy of three different diethylcarbamazine regimens in lymphatic filariasis. Transactions of the Royal Society of Tropical Medicine and Hygiene 89: 319-321, 1995.

4. Biswas G, Raina VK, Rao CK. Revised strategy for the control of lymphatic filariasis in India. Report and recommendations of the WHO sponsored workshop. National Institute of Communicable Diseases and National Malaria Eradication Programme, Ministry of Health and Family Welfare, Government of India, Delhi, 1996.

5. Bockarie MJ, Alexander ND, Hyun P, Dimber Z, Bockarie F, Ibam E, Alpers MP, Kazura JW. Randomised community-based trial of annual singledose diethylcarbamazine with or without ivermectin against Wuchereria bancrofti infection in human beings and mosquitoes. Lancet 351: 162-168, 1998.

6. Centers for Disease Control and Prevention. Recommendations of the International Task Force for Disease Eradication. Morbidity and Mortality Weekly Report 42 (No. RR-16):1-38, 1993.

7. Dreyer G, Addiss D, Santos A, Figueredo-Silva J, Noroes J. Direct assessment in vivo of the efficacy of combined single-dose ivermectin and diethylcarbamazine against adult Wuchereria bancrofti. Transactions of the Royal Society of Tropical Medicine and Hygiene 92: 219-222, 1998.

8. Dreyer G, Coutinho A, Miranda D, Norões J, Rizzo JA, Galdino E, Rocha A, Medeiros Z, Andrade LD. Treatment of bancroftian filariasis in Recife, Brazil: A two-year comparative study of the efficacy of single treatment with ivermectin or diethylcarbamazine. Transactions of the Royal Society of Tropical Medicine and Hygiene 89: 98-102, 1995.

9. Dreyer G, Piessens W. Lymphatic filariasis. In: Nutman TB (ed) Worms and microorganisms can cause lymphatic disease in residents of filariasisendemic areas. Imperial College Press, London. p. 239-256, 1999.

10. Fan PC, Peng HW, Chen CC. Follow-up investigations on clinical manifestations after filariasis eradication by diethylcarbamazine medicated common salt on 
Kihmen (Quemoy) Islands, Republic of China. Journal of Tropical Medicine and Hygiene 98: 461-464, 1995.

11. Gelband H. Diethylcarbamazine salt in the control of lymphatic filariasis. American Journal of Tropical Medicine and Hygiene 50: 655-662, 1994.

12. Harb M, Faris R, Gad AM, Hafez ON, Ramzy R, Buck AA. The resurgence of lymphatic filariasis in the Nile delta. Bulletin World Health Organization 71: 49-54, 1993.

13. Ismail MM, Jayakody RL, Weil GJ, Nirmalan N, Jayasinghe KSA, Abeyewickrema W, Revzi Sheriff $\mathrm{MH}$, Rajaratnam HN, Amaresekera N,Silva DCL, Michalski ML, Dissanaike AS. Efficacy of single-dose combinations of albendazole, ivermectin, and diethylcarbamazine for the treatment of bancroftian filariais. Transactions of the Royal Society of Tropical Medicine and Hygiene 92: 94-97, 1998.

14. Kazura J, Greenberg J, Perry R, Weil G, Day K, Alpers, $M$. Comparison of single-dose diethylcarbamazine and ivermectin for treatment of bancroftian filariasis in Papua New Guinea. American Journal of Tropical Medicine and Hygiene 49: 804-811, 1993.

15. Montestruc E, Courmes E, Fontan R. Endemic lymphangitis in French Guiana and its relation to $W$. bancrofti filariasis. Indian Journal of Malariology 14 : 637-650, 1960.
16. Moulia-Pelat JP, Nguyen LN, Hascoet H, Luquiaud P, Nicolas L. Advantages of an annual single dose of ivermectin $400 \mu \mathrm{g} / \mathrm{kg}$ plus diethylcarbamazine for community treatment of bancroftian filariasis. Transactions of the Royal Society of Tropical Medicine and Hygiene 89: 682-685, 1995.

17. Olszewski WL, Jamal S, Manokaran G, Pani S, Kumaraswami V, Kubicka U, Lukomska B, Dworczynski A, Swoboda E, Meisel-Mikolajczyk F. Bacteriologic studies of skin, tissue fluid, lymph, and lymph nodes in patients with filarial lymphedema. American Journal of Tropical Medicine and Hygiene 57:7-15, 1997.

18. Shenoy RK, Sandhya K, Suma TK, Kumaraswami V. A preliminary study of filariasis related acute adenolymphangitis with special reference to precipitating factors and treatment modalities. Southeast Asian Journal of Tropical Medicine and Public Health 26: 301-305, 1995.

19. World Heath Organization. Bridging the Gaps. World Health Report, Geneva, 1995.

20. World Heath Organization/CTD/TDR. Strategies for control of lymphatic filariasis infection and disease: Report of a WHO/CTD/TDR consultative meeting held at the Universiti Sains Malaysia, Penang, Malaysia, (TDR/CTD/FIL/PENANG/94.1), 1994. 